\title{
MicroRNA-9 regulates survival of chondroblasts and cartilage integrity by targeting protogenin
}

\author{
Jinsoo Song ${ }^{1 \dagger}$, Dongkyun Kim ${ }^{1 \dagger}$, Churl-Hong Chun ${ }^{2}$ and Eun-Jung Jin ${ }^{1 *}$
}

\begin{abstract}
Background: Studies have shown the roles of miR-9 and its validated target, protogenin (PRTG) in the differentiation of chondroblasts to chondrocyte and in the pathogenesis of osteoarthritis (OA). We hypothesized that miR-9 plays a distinct role in endochondral ossification and OA pathogenesis and the present study was undertaken to identify this role. In the studies, chondroblasts were isolated from limb bud of chick and mouse embryos and articular chondrocytes were isolated from rabbit and human cartilage. Osteoarthritic chondrocytes were isolated from cartilage from patients undergoing total knee replacement. Using these cells, we analyzed the changes in the expression of genes and proteins, tested the expression level of miR-9, and applied a target validation system. We also performed functional study of miR-9 and PRTG.

Results: With the progression of chondrogenesis, decreased miR-9 level was observed at the time of numerous apoptotic cell deaths. And chondrocytes isolated from normal human articular cartilage expressed miR-9, and this expression was significantly reduced in OA chondrocytes, especially decreased its expression in parallel with the degree of cartilage degradation. Over-expression of PRTG induced the activation of caspase-3 signaling and increased apoptosis. However, the co-treatment with the miR-9 precursor or PRTG-specific siRNA blocked this apoptotic signaling.

Conclusion: This study shows that PRTG is regulated by miR-9, plays an inhibitory action on survival of chondroblasts and articular chondrocytes during chondrogenesis and OA pathogenesis.
\end{abstract}

Keywords: PRTG, miR-9, Apoptotic cell death, Chondrogenesis, Osteoarthritis

\section{Background}

Chondrogenesis is the earliest phase of skeletal development. Most long bones of vertebrates are formed through the process of endochondral ossification. This well-defined and coordinated process involves mesenchymal cell condensation and chondrogenic differentiation for proper cartilage and bone formation [1]. Several reports have shown that two MAPKs, ERK and p38MAPK, regulate chondrogenesis $[2,3]$. However, despite the importance of these MAPKs in the regulation of cartilage formation, relatively little is known about the involvement of another MAPK signaling pathway, c-jun N-terminal kinase (JNK). Several recent studies demonstrated the importance of JNK signaling during chondrogenesis [4-11]. Activin-A, a

\footnotetext{
*Correspondence: jineunjung@wku.ac.kr

${ }^{\dagger}$ Equal contributors

'Department of Biological Sciences, College of Natural Sciences, Wonkwang University, Iksan, Chunbuk 570-749, South Korea

Full list of author information is available at the end of the article
}

member of the transforming growth factor- $\beta$ family, may suppress chondrocyte differentiation in ATDC5 cells via down-regulation of JNK [4] and reverse signaling of ephrin-B inhibited the attachment and migration of human mesenchymal cells by activating JNK signaling during osteochondral differentiation [5]. Furthermore, in adult articular chondrocytes, MAPK activation is known to associate matrix metalloproteinases (MMPs). Inhibition of JNK signaling inhibits fibronectin fragment stimulation of MMP-13 expression [6,7] and IL-1 stimulation of MMP-13 requires JNK signaling [8]. Our laboratory also showed that JNK signaling is involved in the differentiation of chondroprogenitors in chicks through regulation of miR-34a $[9,10]$ and miR-221 levels [11].

Several reports have suggested a possible role of miRNAs in limb development. In dicer-null mice, a reduced proliferating pool of chondrocytes was observed, and this reduction resulted in severe skeletal growth defects and premature death in the mice [12]. Furthermore, expression of several

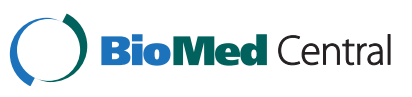


miRs, including miR-10b and miR-196, was detected in the developing limb and found to be involved in the specification of limb development $[13,14]$. However, the precise roles of miRNAs in limb development have not yet been fully established.

Protogenin (PRTG) belongs to the immunoglobulin superfamily and is most closely related to the deleted in colorectal cancer (DCC)-Neogenin subclass [15], which, in addition to DCC and Neogenin, includes Punc and Nope. Recent study showed that PRTG have two proteolytic cleavages. One is between the fibronectin III and the transmembrane domain for ectodomain-shedding, another is by $\gamma$-secretase at the interface of the transmembrane and the intracellular domain to release $\mathrm{C}$-terminal intracellular domain of PRTG. This released C-terminal intracellular domain can translocate to the nucleus to regulate neuronal differentiation [16]. PRTG functions as a receptor to prevent precocious neuronal differentiation in neural progenitors [17] and plays a role in the rearrangement of cells of the paraxial mesodermal lineage [18]. Recently, the expression pattern of PRTG in mouse embryos has been published [19]. As in mouse embryos, PRTG became progressively restricted dorsally in the spinal cord with highest level in the roof plate anterior to the forelimb, suggesting a role during avian limb development. Although several studies emphasize the importance of PRTG during development of various tissues, neither a specific role nor the molecular mechanisms of PRTG action during limb development have been determined. The factors responsible for PRTG regulation are also still unknown. Here, for the first time, we found that PRTG exhibits chondroinhibitory action in limb mesenchymal cells and that PRTG is a direct target of miR-9.

\section{Results}

MiR-9 induces chondro-inhibitory action during chondrogenic differentiation of chick limb mesenchymal cells

From previously reported miRNA array data by inhibition of JNK signaling [11], we identified 14 up-regulated miRNAs and 12 down-regulated miRNAs whose expressions were altered during chondrogenesis (Additional file 1). Among them, miR-9 was one of miRNA whose expression was substantially altered with inhibition of chondrogenic differentiation (determined using a P-value of 0.01 as a cutoff for significance). Inhibition of JNK signaling did not affect other signaling, including Akt and GSK, as confirmed by immunoblotting (Figure 1A). Down-regulation of miR-9 by blockade of JNK signaling was confirmed by quantitative RT-PCR (Figure 1B).

In order to examine the involvement of miR-9 during chondrogenesis, we exposed mesenchymal cells to 200 $\mathrm{nM}$ peptide nucleic acid-based antisense oligonucleotides (ASOs) against miR-9 (miR-9 inhibitor) whose knockdown efficiency was monitored by real time PCR (Figure 1C, upper panel). Precartilage condensation and chondrogenic differentiation were assessed by PA at day 3 and Alcian blue staining at day 5 , respectively. Decreased intensities of PA at day 3 and Alcian blue staining at day 5 were observed with treatment of anti-miR-9 oligonucleotides (Figure 1C, lower panel). Treatment of cells with a miR-9 inhibitor caused a significant decrease in total cell numbers (Figure 1D) with significant increases in apoptotic cell death (Figure 1E) and caspase-3 activity (Figure 1F). Our results revealed that miR-9 inhibitor-induced apoptotic cell death may be responsible for JNK blockade-induced chondro-inhibitory action on precartilage condensation.

\section{MiR-9 stimulated chondrogenic differentiation by regulating protogenin}

Target genes of miR-9 were predicted using miRNA target prediction algorithms, including TargetScan and miRDB and PRTG was identified as a potential target. In support of this prediction, we observed a significant induction in PRTG protein level in miR-9 inhibitor-treated or JNK inhibitor-treated chondroprogenitor cells. And increased protein level of PRTG by JNK inhibitor treatment was significantly reduced with co-introduction of miR-9 (Figure 2A). To confirm that PRTG is a target for miR-9, we cloned the entire 3' UTR of PRTG into a luciferase reporter vector, electroporated the vector into chondrogenic progenitors along with the precursor of miR-9 or a cognate non-targeting negative control, and assayed cell lysates for luciferase expression. We found that cells transfected with the PRTG-3' UTR vector plus miR-9 exhibited significantly less luciferase activity compared to cells that received the vector plus the non-targeting negative control (Figure 2B). Seed sequences of putative targets for miR-9 (Figure 2B upper panel) were exchanged a purine for a pyrimidine and a pyrimidine to a purine. Luciferease activity was not affected with these mutated constructs. Induction of miR-9 successfully reduced PRTG protein level in myc-tagged PRTG/pCAGGS vector electroporated cells (Figure 2C).

To investigate temporal and spatial expression of PRTG, micromass cultures were sectioned longitudinally and immunostained with PRTG antibody (Figure 2E). The RNA level of PRTG was also significantly decreased at 3,6 , and 9 days of culture i.e. at the time of proliferation and condensation with increased expression level of miR-9 and significantly increased at 12,15 , and 18 days of culture, i.e. at the time of hypertrophy and apoptosis with a decreased expression level of miR-9 (Figure 2F).

\section{MiR-9 protects PRTG-induced apoptosis of} chondroprogenitors during chondrogenesis

To observe the effects of PRTG, chondroblasts were electroporated with the myc-tagged PRTG/pCAGGS 


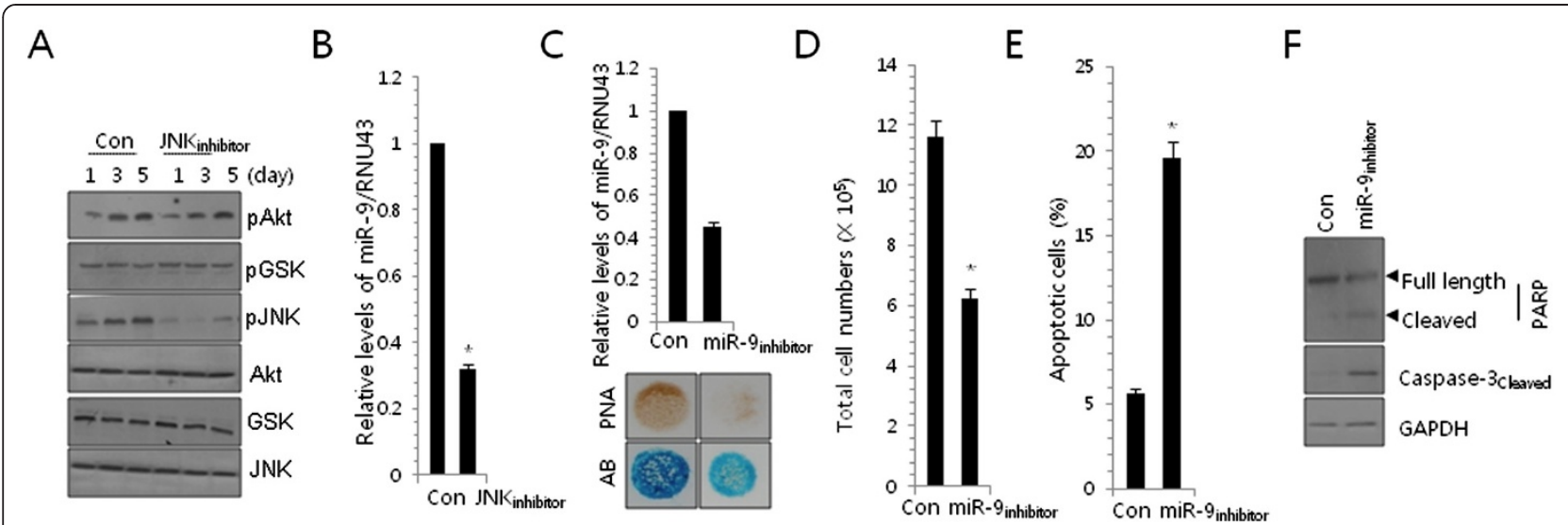

Figure 1 MiR-9 affects cell proliferation and survival during chondrogenesis of chick limb mesenchymal cells. (A) Changes in the phosphorylation levels of Akt, GSK, and JNK were analyzed by Western blotting. (B) Total RNA was purified from chondroprogenitors cultured with or without $5 \mu \mathrm{M}$ JNK inhibitor and the expression of mir-9 was measured with real-time PCR. (C) Chondroprogenitor cells were treated with 100 nM of anti-mir-9 oligonucleotides (mir-9inhibitor). The expression of mir-9 was measured with real-time PCR (upper panel) and Precartilage condensation was analyzed by PA staining at day 3 and Alcian blue staining at day 5 of culture (lower panel). The data shown are representative of at least four independent experiments. The diameter of typical standard culture is $5 \mathrm{~mm}$. (D) Total cell numbers were counted at 2 day of culture. (E) Apoptotic cells were analyzed by FACS analysis. (F) Changes in the cleaved form of caspase-3 were analyzed by Western blotting. Results of cell adhesion experiments were pooled from 5 replicate samples derived from 4 independent experiments. The mean is plotted and the error bars represent $95 \% \mathrm{Cl}$ (lower/upper limit). ${ }^{* *}$, statistically different from control cells $(p<0.001)$.

vector and the transfection efficiency was confirmed by immunoblotting (Figure 3A left upper panel). Precartilage condensation markedly decreases in response to PRTG over-expression (Figure 3A left lower panel). When the micromass cultures were stained with Alcian blue, the number and size of individual cartilage nodules (Figure 3A left lower panel) and staining intensities (Figure 3A right panel) were also noticeably decreased in response to PRTG over-expression. And these inhibitory actions of PRTG on precartilage condensation and chondrogenic differentiation were recovered by co-introduction of miR-9. These data suggested that miR-9 suppresses sulfated proteoglycan accumulation and cartilage nodule formation for chondrogenic differentiation possibly by targeting PRTG.

Since condensation could be due to the modulation of cell number, we next examined whether PRTG suppresses precartilage condensation and chondrogenic differentiation through regulation of cell proliferation or survival. Consistent with suppression of chondrogenesis, cell proliferation was significantly decreased in PRTG over-expressed cells (Figure 3B left panel). Furthermore, decreased in total cell number by JNK inhibitor or PRTG was reversed by co-introduction of PRTG siRNA or miR-9, respectively (Figure 3B, right panel). Apoptotic cell death, as assessed by FACS analysis (left panel) and by caspase-3 activity (right panel), was increased by the introduction of PRTG or treatment of JNK inhibitor and inhibited by co-induction of miR-9 (Figure 3C). As well, inhibited precartilage condensation by JNK inhibition and PRTG over-expression was recovered by co-electroporation of PRTG-specific siRNA or co-introduction of miR-9 (Figure 3D) confirmed its efficiency with PRTG over-expressed cells (Figure 3C lower panel).

To further investigate miR-9 involvement in limb formation, $18 \mathrm{HH}$ stage chick embryos were treated with JNK inhibitor in the absence or presence of miR-9 inhibitors. We observed the disruption of limb formation, especially formation of inter-digital regions, in JNK inhibitor-treated chick embryos. This malformation was overcome by co-treatment of miR-9 inhibitor (Figure 3E). These results indicate that negative regulation of chondrogenesis by the over-expression of PRTG is mediated by modulating apoptotic death of chondrogenic competent cells.

\section{MiR-9 also protects PRTG-induced apoptosis of chondrocytes}

In order to further study the role of miR-9 in survival of chondrocytes, dedifferentiation of articular chondrocytes was induced by IL- $1 \beta$ exposure. We confirmed that IL- $1 \beta$ exposure to cells decreased the expression level of miR-9 (Figure 4A). It has been shown that differentiated chondrocytes could lose their intrinsic characteristics upon exposure to IL-1 $\beta[20,21]$, nitric oxide [22], or retinoic acid [23,24], and during serial monolayer culture $[25,26]$ through a process designated "dedifferentiation". Dedifferentiation was confirmed by a degenerated morphology (Figure 4B and 4C upper panel). A more significant degenerative phenotype and decreased level of type II collagen were observed in co-treatment of miR-9 inhibitor with IL-1 $\beta$ (Figure $4 \mathrm{~B}$ ) and IL-1 $\beta$-induced degenerative changes were prevented by co-introduction of miR-9 


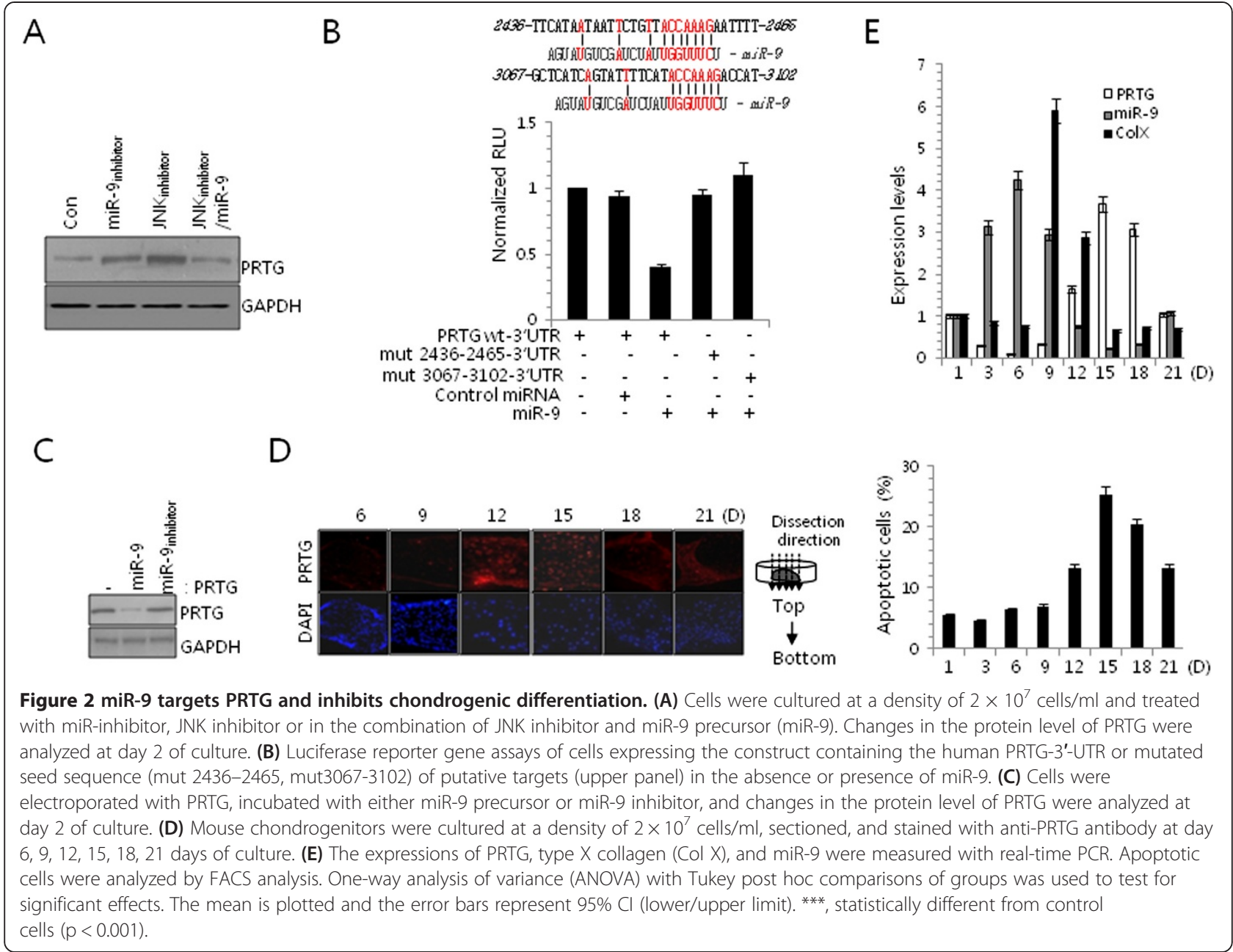

(Figure 4C). Consisted with these observations, the protein level of PRTG was increased by co-treatment of miR-9 inhibitor (Figure 4B) and decreased by cointroduction of miR-9 (Figure 4C). The total cell number of rabbit articular chondrocytes and human articular chondrocytes was decreased with IL- $1 \beta$ treatment. A more significant decrease was observed with co-treatment of miR-9 or PRTG (Figure 4D).

For further investigation of involvement of miR-9 or PRTG, macroscopically normal human cartilage from 10 adult donors from both genders (mean age 37.4 years; age range $20-60$ years), without history of joint disease was confirmed that the specimens were histological normal cartilage and used for isolating primary articular chondrocytes. A significant degenerative phenotype was observed with IL-1 $\beta$-treated or PRTG-introduced chondrocytes (Figure 4E left panel). Most significant degeneration was observed in the combination of IL-1 $\beta$ and PRTG-treated cell or in the combination of IL-1 $\beta$ and miR-9 inhibitor-treated cell. However, IL-1 $\beta$-induced degeneration was significantly blocked by co-introduction of miR-9. We also observed that increased apoptotic cell death by IL-1 $\beta$ was blocked by co-introduction of miR-9 (Figure $4 \mathrm{E}$ right panel). In addition, co-introduction of PRTG or inhibition of miR-9 significantly increased apoptosis in cells treated with TGF$\beta 3$ (Figure 4F), a known positive regulator of chondrocytes [27]. For further validation for apoptotic involvement of miR-9 and PRTG, normal chondrocytes were introduced with miR-9 in the absence or presence of IL-1 $\beta$ or PRTG and expression levels of genes involved in apoptosis was examined (Figure 5). Apoptotic genes including ABL1, ATP6V1GNOL3, CASP1, 3, 7, CD40, CYLD, and FAS were induced with IL-1 $\beta$ treatments or PRTG over-expression whereas expression levels of those genes were decreased with miR-9 introduction.

\section{MiR-9 also involves in the pathogenesis of osteoarthritis}

To investigate the pathological involvement of miR-9, 10 osteoarthritic (OA) cartilage was obtained from patients diagnosed with $\mathrm{OA}$ according to the American College of Rheumatology (ACR) criteria, which underwent joint surgery (mean age 64.6 years; age range $52-71$ years). 


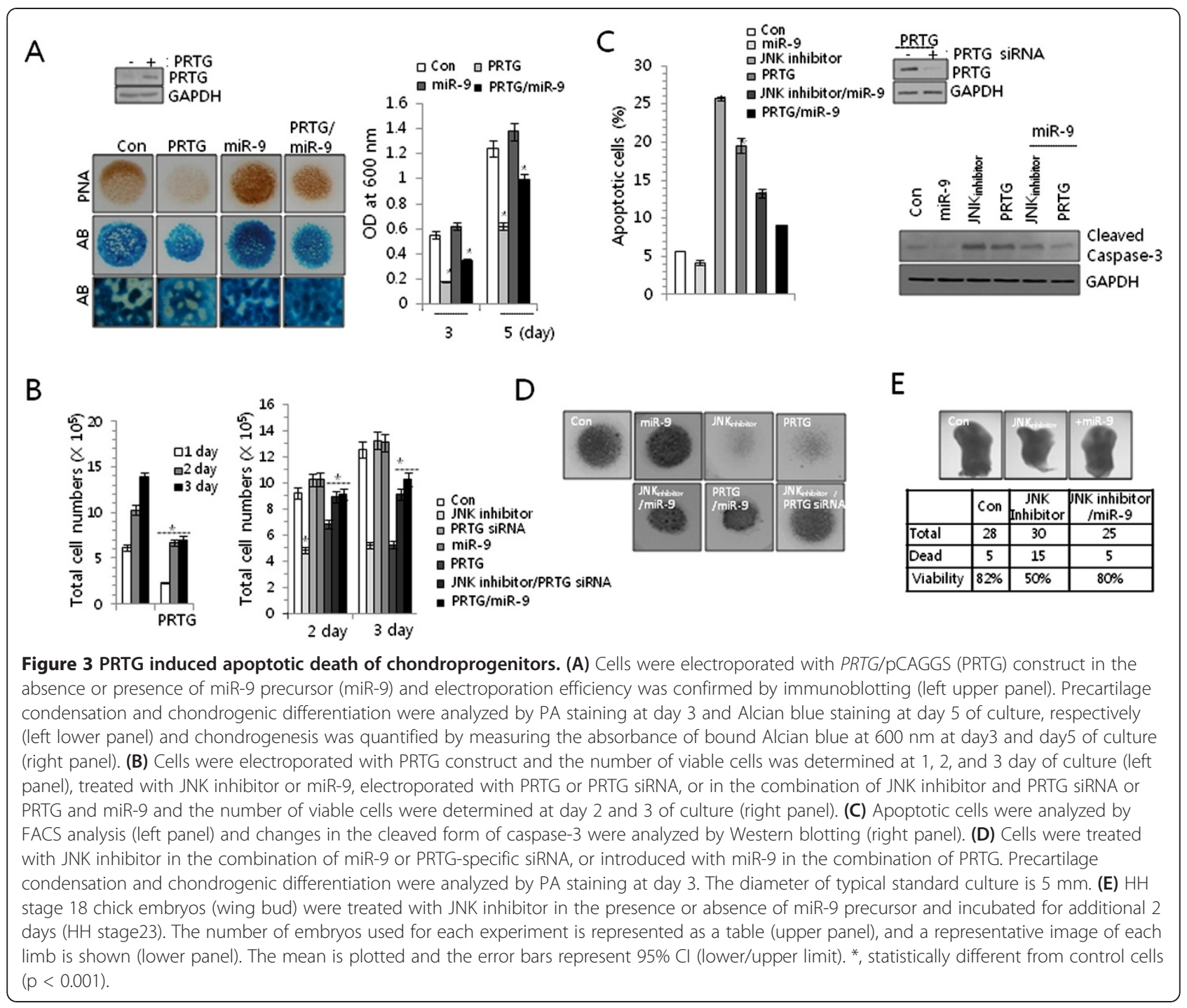

Knee radiographs from the OA participants were classified as grade IV according to the Kellgren and Lawrence $(\mathrm{K} / \mathrm{L})$ scoring system (Figure 6A). OA cartilage was divided into non-OA region (A), mild-OA region (B), and severe-OA region (C, Figure $6 \mathrm{~A}$ upper panel) as confirmed by a degenerative morphology with OA progression (Figure 6A middle panel) and staining with Safranin $\mathrm{O}$ and Alcian blue (Figure 6A lower panel).

Proteolytic degradation of cartilage is a hallmark of OA and activated chondrocytes are known to produce matrixdegrading enzymes such as collagenase 3 (MMP-13) in OA joints [28]. Expression of MMP-13 in mice resulted in pathologic changes in the joints, similar to human OA [28]. In addition, the proinflammatory cytokine interleukin1 (IL-1 $\beta$ ) and MMP-13 localize to the site of cartilage degradation in $\mathrm{OA}$ joints, providing evidence of their key roles in the pathogenesis of OA $[29,30]$. Consistent with previous reports $[28,30]$, the expression levels of MMP-2,
-12 , and -13 (Figure 6B) were increased. Furthermore, cell viability was significantly decreased in area $C$ and the caspase-3 activity was significantly increased in area B and $C$ (Figure $6 \mathrm{C}$ ). The protein and RNA levels of type II collagen and miR-9 were decreased whereas those levels of PRTG were increased as the progression of cartilage damage (Figure 6D).

To validate the role of miR-9 in chondrocyte apoptosis during OA cartilage destruction in vivo, we overexpressed miR-9 in cartilage tissue by injecting miR-9-expressing or si-miR-9 expressing lentiviruses into DMM mouse knee joints (Figure 6E). Cartilage destruction as visualized by safranin-O staining was significantly induced by DMM surgery. Semi-quantitative scoring for cartilage destruction [31] using safranin-O photomicrographs of medial femoral condyle (MFC) and medial tibial plateau (MTP) indicated that DMM surgery scored as 0.5 by MFC view and 2 by MTP view. Most severe cartilage destruction was observed 


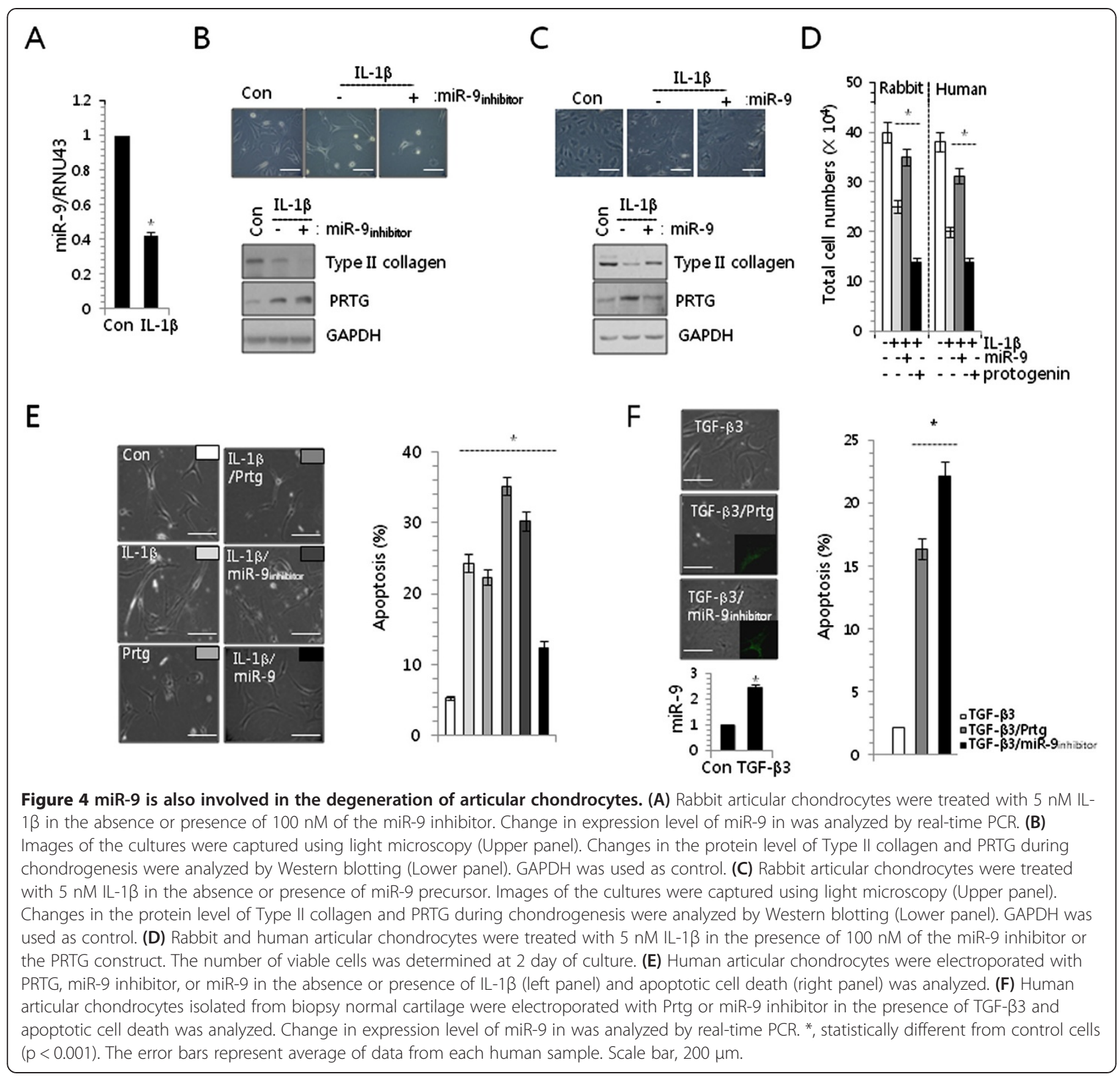

\begin{tabular}{|l|lll|lllll|}
\hline ABL1 & CASP2 & APAF1 & ATP6V1G & ABL1 & CASP2 & APAF1 & ATP6V1G \\
NOL3 & BCL2L1 & BCL2L11 & GADD45 & NOL3 & BCL2L1 & BCL2L11 & GADD45A \\
\hline DFFA & CD40 & TNF & BIRC2 & DFFA & CD40 & TNF & BIRC2 \\
CASP7 & CASP9 & TP53 & IGF1R & CASP7 & CASP9 & TP53 & IGF1R \\
\hline BCL2A1 & CASP3 & CASP1 & CD40LG & BCL2A1 & CASP3 & CASP1 & CD40LG \\
CFLAR & APP & CYLD & BAX & CFLAR & APP & CYLD & BAX \\
FASLG & FAS & CASP6 & DEF & FASLG & FAS & CASP6 & DEF \\
\hline
\end{tabular}

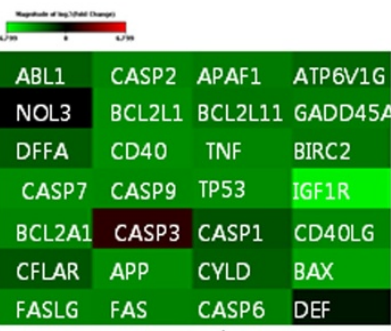

IL-1 $1 /$ miR-9

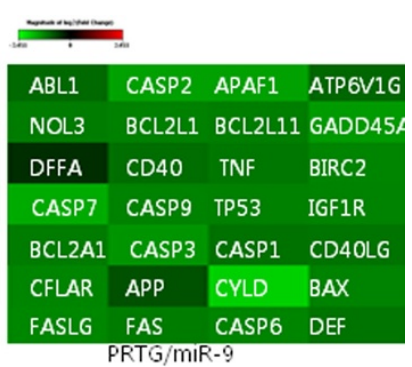

Figure 5 miR-9 and its target, PRTG is involved in chondrocyte apoptosis. Human articular chondrocytes isolated from biopsy normal cartilage were electroporated with Prtg or miR-9 in the absence or presence of $\mathrm{IL}-1 \beta$ and expression levels of apoptotic genes were examined and represented as heat-map. 


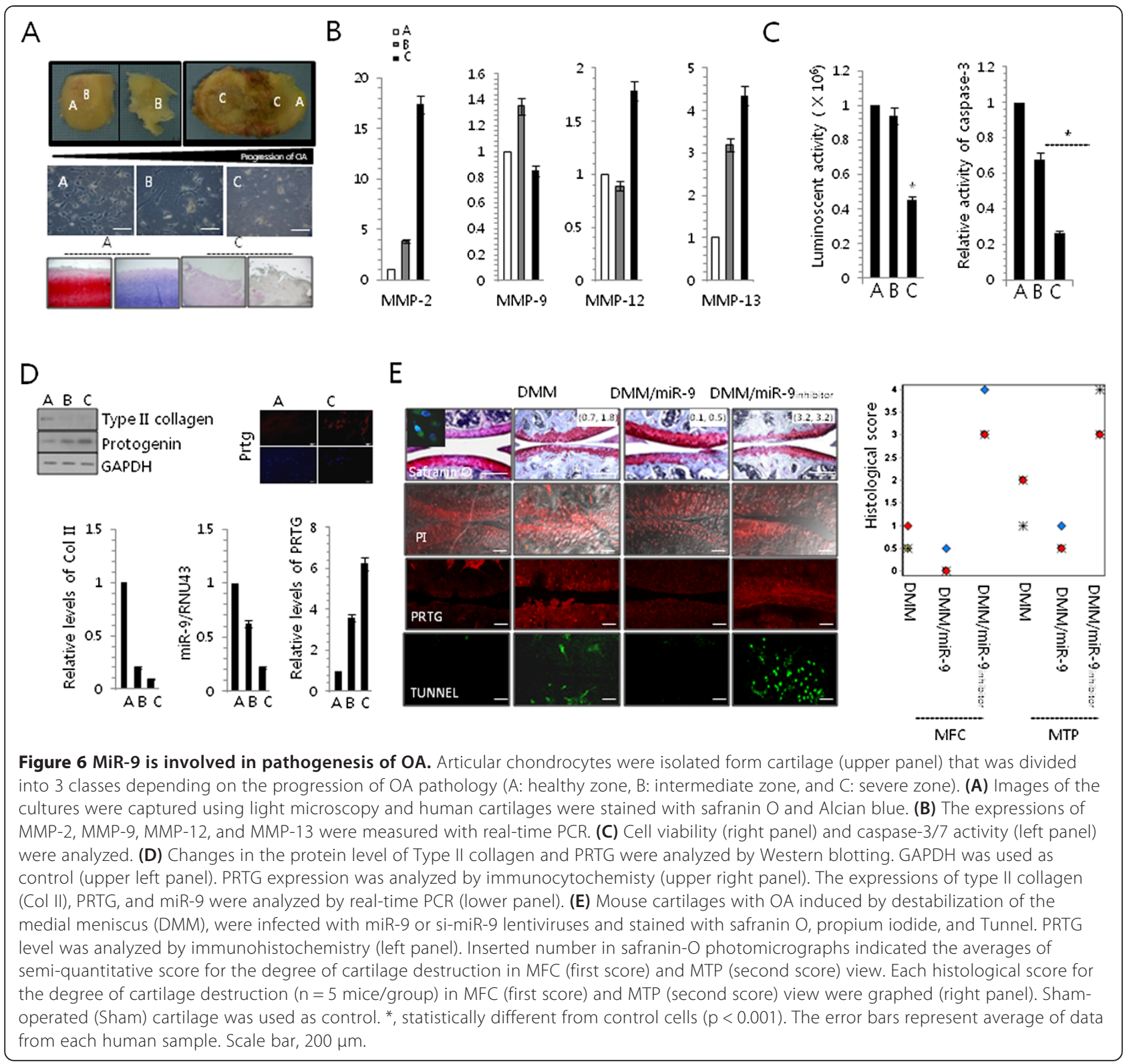

with the infection of si-miR-9 expression lentiviruses (MFC score of 3, MTP score of 3). However, over-expression of miR-9 significantly reduced cartilage destruction (MFC score of 0, MTP score of 0.5). Consistent with this, increased apoptosis of articular chondrocytes and PRTG level by DMM surgery was also inhibited with overexpression of miR-9 and stimulated with suppression of miR-9.

\section{Discussion}

During development, most of our bones form through endochondral ossification in which bones are first laid down as cartilage precursor [1] and mitogen-activated protein kinase (MAPK) cascades are known to play essential roles in regulating mesenchymal cell chondrogenesis [2,3]. Particularly, our recent study showed the involvement of JNK signaling during chondrogenesis of limb mesenchymal cells [11]. We reported the involvement of several miRNAs including miR-34a $[9,10]$ and miR-221 [11] in JNKregulated chondrogenic differentiation. Here, we found another miRNA, miR-9 involved in JNK-induced chondrogenic differentiation. Furthermore, we suggested that miR-9 is one of important players in OA pathogenesis.

MiRNAs play key roles in diverse regulatory pathways, including cell proliferation, differentiation, apoptosis, and many other physiological and pathological processes $[32,33]$. However, the precise roles of miRNAs in cartilage biology are largely unknown. Here, we investigated the 
functional importance of miR-9 both in endochondral ossification and OA pathogenesis.

MiR-9 provides a model for controlling the balance between neural stem cell proliferation and differentiation [34]. MiR-9 is known as a growth inhibition factor and plays a role as in anti-proliferative activity in human gastric adenocarcinoma cells by negatively targeting NF-kB1 at the post-transcriptional level [35]. Jones and colleagues (2009) suggest the involvement of miR-9 in OA bone and cartilage by mediating the IL- $1 \beta$-induced production of TNF- $\alpha$ [36]. Here, we show that miR-9 targets PRTG, thus revealing a potential mechanism for apoptotic death of limb chondroblasts during endochondral ossification. Experimental evidence indicates that PRTG is a target of miR-9. First, the ability of miR-9 to regulate PRTG expression is likely direct, because it binds to the 3'UTR of PRTG mRNA. Second, the luciferase intensity of PRTG-UTR was specifically responsive to miR-9 overexpression suggesting that miR-9 may regulate PRTG protein expression by inducing translational suppression. Consistent with the results obtained with PRTG overexpression, knock-down of miR-9 promoted the apoptotic death of limb chondroblasts. Our study provides evidence for the mechanism through which miR-9 affects the survival/proliferation of chondrocytes and PRTG is one of the physiologic targets of miR-9 in the regulation of chondrocyte survival.

In this study, we also sought to determine the effect of PRTG in chondrogenic differentiation and the regulatory mechanism of PRTG, a member of the immunoglobulin superfamily that is most closely related to DCC-Neogenin subclass [37]. The ability of Neogenin to regulate cell death appears to be dependent on the context of its expression, i.e. certain cell types respond differently to cell death signaling. Over-expression of Neogenin in chick dorsal root ganglion neurons has no noticeable effect on cell survival [37], whereas in PC12 cells, Neogenin induces apoptosis [38]. Knockdown of Neogenin in zebrafish increased apoptotic cell death and reduces neuronal differentiation [39]. Our results revealed for the first time that PRTG exerts chondro-inhibitory effects through up-regulation of apoptotic cell death on limb chondroblasts.

Here, we also suggest the involvement of miR-9 in OA pathogenesis as well as chondrogenic differentiation of limb mesenchymal cells. OA is a progressive degenerative disease characterized by cartilage degradation and chondrocyte apoptosis. In addition, chondrocyte apoptosis in osteoarthritic cartilage has been reported in dogs, humans, and horses $[40,41]$ and is considered to be one of the major factors in the pathogenesis of the OA disease process. Here, we also found that cell viability was decreased in degenerated rabbit and human articular chondrocytes and miR-9: PRTG interplay is involved in the apoptotic process of IL- $1 \beta$-induced degeneration. It has been shown that miR-9 is responsible for regulating viability of chondrocytes and reduction of miR-9 was observed in generative chondrocytes and this could be a reason for decreasing cell viability.

The primary pathogenic events in OA include loss and abnormal remodeling of cartilage extracellular matrix. Chondrocytes are the major cell type of the articular cartilage and function to maintain tissue homeostasis. Recent findings indicate that chondrocyte death and survival are closely linked with cartilage matrix integrity [42]. Two key targets of cartilage degeneration during OA are type II collagen and aggrecan [43]. The accumulation of degraded fragments over time increase MMP-13 synthesis and leads to positive feedback loop through interaction with cell-surface integrins resulting destruction of knee joints [44]. Yang and collegues (1997) found increased chondrocyte apoptosis in transgenic mice lacking type II collagen [45]. Our laboratory (2010) also showed that degradation of type I collagen by MMP-9 stimulated cell death, by interfering with cell attachment and integrin-mediated survival signaling [46]. These previous reports suggest that degradation of cartilage matrix could be an inducer for chondrocyte apoptosis. However, it still remains unclear whether chondrocyte apoptosis is a cause of, or the result of, cartilage matrix breakdown. Cells require attachment to the extracellular matrix (ECM) for survival, function, and growth. A disruption of the collagen network could disturb chondrocyte anchorage to the ECM and result in chondrocyte apoptosis. Alternatively, cartilage homeostasis could not be maintained due to chondrocytes apoptosis, and therefore cartilage degradation could be induced.

We observed an increased protein level of MMP-13, a major cartilage degrading enzyme, with increasing stages of OA pathogenesis. In OA, a progressive degenerative disease, proteolytic degradation of cartilage by matrixdegrading enzymes, such as MMP-13 [47,48] and ADAMTS5 $[49,50]$, is a hallmark. MiR-146a functions in an anti-catabolic manner in articular cartilage by antagonizing the IL-1 $\beta$-induced expression of cartilagedegrading enzymes MMP13 [51] and ADAMTS5 [52]. Reduced miR-140 expression was observed in human OA cartilage [53,54]. MiR-140 plays dual roles in both cartilage development and homeostasis, in part via by regulating Adamts-5 in OA [55]. Our laboratory is currently undergoing study on the relationships between miR-9, PRTG, and MMP-13 to verify whether chondrocyte apoptosis by PRTG, a target for miR-9, is down-stream, up-stream, or independent of MMP-13 induction.

In sum, here, for the first time, we found that PRTG is regulated by miR-9, resulting in an inhibition of cell proliferation and survival in chondrogenic progenitors and articular chondrocytes. Reduction of miR-9 induction, which results in increased PRTG levels in OA pathogenesis, 
may be responsible for chondrocyte apoptosis, a typical hallmark of OA.

\section{Methods}

\section{Primary cell cultures}

Mesenchymal cells (at a density of $2 \times 10^{7}$ cells $/ \mathrm{ml}$ ) were derived from the distal tips of Hamburger-Hamilton $(\mathrm{HH})$ stage 22/23 embryo limb buds of fertilized White Leghorn chicken eggs or E11.5 embryos. They were micromass cultured in Ham's F-12 medium containing $10 \%$ fetal bovine serum (FBS), $100 \mathrm{IU} / \mathrm{ml}$ penicillin, and $100 \mu \mathrm{g} / \mathrm{ml}$ streptomycin (Gibco Invitrogen, Grand Island, $\mathrm{NY}$ ). A concentration of $5 \mu \mathrm{M}$ was chosen for JNK inhibitor II (Calbiochem, San Diego, CA) and treated for entire culture period in this study.

Rabbit articular chondrocytes from joint cartilage slices of 2-week-old New Zealand white rabbits were isolated with $0.2 \%$ collagenase type II, as described previously [56] and were then plated on culture dishes at a density of $5 \times 10^{4}$ cells $/ \mathrm{cm}^{2}$. The medium was replaced every 2 days after seeding.

Human articular cartilage specimens were obtained from cartilages that were undergoing total knee arthroplasty. Tissue collection was approved by the Human Subjects Committee of Wonkwang University. Chondrocytes were extracted as previously described [57] and seeded at a density of $1.5 \times 10^{4}$ cells $/ \mathrm{cm}^{2}$ in DMEM (GibcoInvitrogen) supplemented with $10 \%$ fetal bovine serum (FBS), 100 units $/ \mathrm{ml}$ penicillin, and $100 \mu \mathrm{g} / \mathrm{ml}$ streptomycin (Gibco Invitrogen). A concentration of $5 \mathrm{ng} / \mathrm{ml}$ was chosen for IL-1 $\beta$ ( $R$ \& D systems, Minneapolis, MN) in this study.

\section{Analysis of cell differentiation and precartilage condensation}

Alcian blue bound to sulfated glycosaminoglycans was extracted with $6 \mathrm{M}$ guanidine- $\mathrm{HCl}$, and quantified by measuring the absorbance of the extracts at $600 \mathrm{~nm}$. Cultures were incubated with $100 \mu \mathrm{g} / \mathrm{ml}$ biotinylated peanut agglutinin (PA, Sigma) and visualized with the VECTASTAIN ABC and DAB substrate solution kit (Vector laboratories Inc., Burlingame, $\mathrm{CA}$ ).

\section{Apoptosis assay}

Apoptosis was analyzed by a flow cytometer (FACS calibure, Becton-Dickinson, France). To detect extent of propidium iodide, cells were excited at $488 \mathrm{~nm}$ and emission was observed at $585 \mathrm{~nm}$.

\section{Caspase assay}

Activities of caspase- 3 and caspase- 7 were determined using a caspase colorimetric assay kit (R\&D Systems Inc., Minneapolis, MN, USA).

\section{Cell viability assay}

Cell viability was assayed using CellTiter-Glo luminescent cell viability assay kit (Promega), which determines viability based on the quantification of ATP present in metabolically active or viable cells [58].

\section{Cell proliferation assay}

Proliferation was determined by direct counting of cells. Control and treated cultures were detached with trypsin/ EDTA solution and counted in triplicate using a hematocytometer.

\section{Western blot analysis}

Total proteins $(30 \mu \mathrm{g})$ were electrophoresed and transferred to nitrocellulose membranes (Schleicher and Schuell, Keene, Germany). The membranes were individually probed with antibodies specific for Type I, II collagen, PRTG (Calbiochem, La Jolla, CA), (p)AKT, (p)GSK, (p)JNK, GAPDH (Santa Cruz Biotechnology Inc.), Caspase-3, PARP (Cell Signaling Technology Inc., Danvers, MA, USA). The blots were developed using a peroxidase-conjugated secondary antibody, and the immunoreactive proteins were visualized with an ECL system (Amersham, UK).

\section{Electroporation}

Chondrogenic progenitors were electroporated with either a myc-tagged PRTG (PRTG) expression vector (a kind gift from Dr. D. Watanabe at Department of Molecular Neurobiology, Institute of Development, Aging and Cancer, Tohoku University, Japan; pCAGGS was used as mock) or PRTG-specific siRNA (purchased from Invitrogen, PRTG_stealth primers; 5'-UUUACAGGUAA AUCGAGCUACUCCA-3', 5'-UGGAGU AGCUCGAU UUACCUGUAAAA-3') using a BTX-830 square wave generator (Gentronics, San Diego, CA) with $20 \mathrm{msec}$, 200 square pulses.

\section{MiRNA and mRNA real-time quantitative RT-PCR}

MiRNA and mRNA expression were independently quantified using the TaqMan MicroRNA and TaqMan gene expression assays (Applied Biosystems), respectively, according to the manufacturer's protocols. MiRNA expression was normalized to RNU43 small nuclear RNA endogenous controls.

For mRNA, transcripts were quantified by real-time quantitative polymerase chain reaction (RT-PCR) and normalized to the amount of GAPDH mRNA expressed The oligonucleotides used as primers were listed in Table 1. 
Table 1 The list of primers

\begin{tabular}{|c|c|c|}
\hline Mouse gene & Primers & \\
\hline PRTG & 5'-aagtcaatgacgggcatcgcagta-3' & $5^{\prime}$-acttcctggcttgcttcggtaga-3' \\
\hline Type X collagen & 5'-ataagaacggcacgcctaagatgt-3' & 5'-ctgcattggg cattggagccata-3' \\
\hline GAPDH & $5^{\prime}$-tgtccgtcgtggatctgac-3' & $5^{\prime}-$ cctgcttcaccaccttcttg-3' \\
\hline Human gene & Primers & \\
\hline type II collagen & 5'-tcactcatgccctgaag-3' & 5'-ctatgtccatgggtgcaatg-3' \\
\hline PRTG & $5^{\prime}$-tgcatgcaagat tcatcccaccc-3' & 5'-tgcaatactcctgttggtagggca-3' \\
\hline MMP-2 & 5'acaccaagaacttc gtctg-3' & 5'-tgcagatctcaggagtgaca-3' \\
\hline MMP-9, & 5'-atttctgccaggaccgcttctact-3' & 5'-atgtcataggtcacgtagcccact-3' \\
\hline MMP-12 & 5'-gaaccaacgcttgccaaatcctga-3' & 5'-ttcccacggtagtgacagcatcaa-3' \\
\hline MMP-13 & 5'-ttgcagagcgctacctgagatcat-3' & $5^{\prime}$-tttgccagtcacctctaagccgaa-3' \\
\hline ABL1 & 5'-gaagcccaaaccaaaaatgg-3' & $5^{\prime}$-gactgttgactggcgtgatgtag-3' \\
\hline AFAF1 & $5^{\prime}-\operatorname{tgcgctg} c t c t g c c t t c t-3^{\prime}$ & 5'-gcggagcacacaaatgaaga-3' \\
\hline APP & 5'-tgtccgcgc agaacagaa-3' & 5'-tgtccgcgcagaacagaa-3' \\
\hline ATP6V1G2 & $5^{\prime}$-ggaaaacatcctgacttcagtgtct-3' & 5'-ccagcaagtgacagggtcaa-3' \\
\hline BAX & 5'-ccaaggtgccgg aactga-3' & 5'-cccggaggaagtccaatgt-3' \\
\hline BCL2A1 & 5'-cctggatcaggtccaagcaa-3' & $5^{\prime}$-ttggactgagaacgcaacattt-3' \\
\hline BCL2L11 & 5'-gctttcccatggtcacaggat-3' & $5^{\prime}$-ctgcagctggactctgctgta-3' \\
\hline BIRC2 & $5^{\prime}$-cctgtggtgggaagctcagt-3' & $5^{\prime}$-cctccg gtgttctgacatagc-3' \\
\hline CASP1 & 5'-at accaagaactgcccaagtttg-3' & 5'-ggcaggcctggatgatga-3' \\
\hline CASP2 & 5'-ggtaaagaaaagttgccgaagatc-3' & $5^{\prime}$-ggcatag ccgcatatcatgtc-3' \\
\hline CASP3 & 5'-gcc tacagcccatttctccat-3' & $5^{\prime}$-gcgccctggcagcat-3' \\
\hline CASP6 & $5^{\prime}$-ggcgtggttactcacacctgta-3' & $5^{\prime}$-gatccgeccaccttgga-3' \\
\hline CASP7 & $5^{\prime}$-ccgccgtgggaacgat-3' & $5^{\prime}-$ cctcaaccccctgctcttc-3' \\
\hline CASP9 & $5^{\prime}$-agcagtgggctcactctgaag-3' & $5^{\prime}$-aacagcattagcgaccctaagc-3' \\
\hline CD40 & $5^{\prime}$-tggtgagtgactgcacagagttc-3' & 5'-cgctttcaccgcaagga-3' \\
\hline CD40LG & 5'-ccaggtgcttcggtgtttgt-3' & 5'-ccagtgccatggctcactt-3' \\
\hline CFLAR & $5^{\prime}$-gctggcagctgattagatggt-3' & 5'-tttgagtcagtggactgggaaa-3' \\
\hline CYLD & 5'-tgtggagggcttgcaatgt-3' & $5^{\prime}$-agctgagatgtcc ggatcgt-3' \\
\hline DEFB1 & 5'-ttgacgctccctgctcaga-3' & 5'-tggacggtggcacaactct-3' \\
\hline FAS & 5'-acccgctcagtacggagttg-3' & 5'-ccagcatggttgtt gagcaa-3' \\
\hline FASLG & $5^{\prime}$-tgcctcctcttgagcagtca-3' & $5^{\prime}$-tcctgtagaggctgaggtgtca-3' \\
\hline GADD45A & $5^{\prime}$-gatgtggctctgcagatcca-3' & 5'-atgtcgttctcgc agcaaaa-3' \\
\hline IGF1R & $5^{\prime}$-cttgtacattcgca ccaatgct-3' & $5^{\prime}$-cgattaactgagaagaggagttcga-3' \\
\hline NOL3 & 5'-gcccaccacgagcatca-3' & $5^{\prime}$-cctggactcctaag ggcagat-3' \\
\hline TNF & 5'-gcccaccacgagcatca-3' & 5'-cctggactcctaag ggcagat-3' \\
\hline TP53 & 5'-tgcaataggtgtgcgtcagaa-3' & 5'-ccccg ggacaaagcaaa-3' \\
\hline GAPDH & 5'-gatcatcagcaatgcctcct-3' & $5^{\prime}$-tgtggtcatgagtccttcca-3' \\
\hline
\end{tabular}

$A B L 1 \mathrm{c}$-abl oncogene1, non receptor tyrosine kinase, AFAF1 apoptotic peptidase activating factor1, APP amyloid beta-A4 pre cursor protein, ATP6V1G2 ATPase, $\mathrm{H}+$ transporting lysosomal $13 \mathrm{kDa}$, V1 subunit $\mathrm{G} 2, B A X \mathrm{BCL} 2$-associated $\times$ protein, $B C L 2 A 1$ BCL2-related protein A1, BCL2L1 BCL2-like 1, BCL2L11 BCL2-like 11, B, IRC2 baculoviral IAP repeat containing 2, CASP1 caspase 1- apoptosis-related cysteine peptidase, CASP3 caspase 3- apoptosis-related cysteine peptidase, CASP9 caspase 9- apoptosis-related cysteine peptidase, CD40 CD40 molecule, TNF receptor super family member 5, CD40LG CD40 ligand, CFLAR CASP8 and FADD-like apoptosis regulator, CYLD cylindromatosis-turban tumor syndrome, DEFB1 defensin, beta 1, DFFA DNA fragmentation factor, $45 \mathrm{kDa}$, alpha polypeptide, FAS Fas-TNF receptor super family, member 6, FASLG Fas ligand-TNF super family, member 6, GADD45A growth arrest and DNA-damage-inclucible, alpha, IGF1R insulin-like growth factor 1 receptor, NOL3 necleolar protein 3-apoptosis repressor with CARD domain, TNF tumor necrosis factor, TP53 tumor protein p53. 
Synthesis of a PNA (peptide nucleic acid)-based miRNA inhibitor and induction in cells

PNA, an artificially created DNA analogue, exhibits superior binding affinity and chemical/biological stability because the phosphate ribose ring of DNA is replaced with a polyamide backbone. The PNA-based ASOs, which contain an O-linker at the $\mathrm{N}$ terminus of the PNA to improve solubility, were purchased from Panagene (Korea). A scrambled PNA-based ASO was used as a negative control (5'-RRRQRRKKR-00-ATTAATGT CGGACAA-3', RRRQRRKKR: cell penetrating peptide; O:AEEA linker) and $200 \mathrm{nM}$ of PNA-based ASO (PNA9: UCUUUGGUU AUCUAGCUGUAUGA) were electroporated into isolated mesenchymal cells.

\section{Reporter vectors and DNA constructs}

The 3'-UTR of human PRTG (PRTG) was PCR amplified using the following primers: 5 '-TGGGAGCTCCTGGCT CTATT-3' (bp no. 1616 1635), 5'-GCTGAGGCTGAC TTT GCACT-3' (bp no. 3088 3107). It was then cloned downstream of the CMV-driven firefly luciferase cassette in the pMIR-REPORT vector (Ambion). For miRNA target validation, chondroblasts were electroporated with $200 \mathrm{ng}$ of a firefly luciferase reporter construct, 50 pmol of pre-miR-9 or pre-miR-negative (Ambion). The Renilla luciferase vector was used to normalize electroporation efficiency. At $24 \mathrm{hr}$ after electroporation, both firefly and Renilla luciferase activity were assayed (Promega). Normalized relative light units represent firefly luciferase activity or Renillar luciferase activity.

\section{Arthritic cartilage, experimental $\mathrm{OA}$, and histology of $O A$ cartilage}

International Cartilage Repair Society (ICRS) grade 10 human OA cartilage was sourced from individuals (age 51-72 years) undergoing arthroplasty for OA of the knee joint. The Wonkwang University Hospital Institutional Review Board approved the use of these materials, and all individuals provided written informed consent before the operative procedure. Human OA cartilage samples were frozen, sectioned at a thickness of $10 \mu \mathrm{m}$, fixed in paraformaldehyde, and stained with Alcian blue.

Experimental OA was induced by destabilization of the medial meniscus (DMM) surgery 8-week-old male mice. Sham-operated animals injected with empty lentiviruses (mock transduction) were used as controls for DMM. Mice were killed 8 weeks after DMM surgery or 2 weeks after intraarticular injection $\left(1 \times 10^{9}\right.$ plaqueforming units (PFU)) of miR-9-expressing lentiviruses (lenti-miR-9) for histological and biochemical analyses. Cartilage destruction in mice was examined using Safranin $\mathrm{O}$ staining. Briefly, knee joints were fixed in $4 \%$ paraformaldehyde, decalcified in 0.5 M EDTA (pH 7.4) for 14 days at $4^{\circ} \mathrm{C}$, and embedded in paraffin. The paraffin blocks were sectioned at $6 \mu \mathrm{m}$ thickness. The sections were deparaffinized in xylene, hydrated with graded ethanol, and stained with Safranin O.

\section{Tunnel assay}

Apoptosis of articular chondrocytes in cartilage tissues was determined by TUNEL assay using a kit from Clontech (Mountain View, CA). Specimens were visualized under a fluorescence microscope.

\section{Immunohistochemistry}

Deparaffinized section was incubated with the anti-PRTG antibody (1: 200 dilutions) overnight at $4{ }^{\circ} \mathrm{C}$, followed by incubation with rhodamine-conjugated secondary antibody at room temperature for 1 hour. Specimens were visualized under a fluorescence microscope.

\section{Statistical analysis}

Statistical analysis was performed using the SPSS program for Windows, Standard Version (version 18.0, SPSS Inc., Chicago, http://www.SPSS.com).

\section{Additional file}

Additional file 1: Differentially expressed miRNAs at $48 \mathrm{hr}$ after suppression of JNK signaling in limb mesenchymal cells.

\section{Competing interests}

The authors declare that they have no competing interests.

\section{Authors' contributions}

All authors were involved in drafting the article critically for important intellectual content. EJJ and CHC had full access to all of the data in the study and take responsibility for the integrity of the data and the accuracy of the data analysis. Study conception and design. JS, ML, DK, CHC, EJJ Acquisition of data. JS, DK, Analysis and interpretation of data. ML, CHC, EJJ. All authors read and approved the final manuscript.

\section{Acknowledgments}

This works was supported by National Research Foundation (NRF) of Korea Grant funded by the Korean Governments by the Ministry of Education (2012R1A1A2039074) and MSIP [2011-0030716], by a grant of the Korean Health Technology R\&D Project, Ministry of Health \& Welfare, Republic of Korea (A111329)

\section{Author details}

${ }^{1}$ Department of Biological Sciences, College of Natural Sciences, Wonkwang University, Iksan, Chunbuk 570-749, South Korea. ${ }^{2}$ Departments of Orthopedic Surgery, Wonkwang University School of Medicine, Iksan, Chunbuk 570-749, South Korea.

Received: 11 May 2013 Accepted: 23 August 2013

Published: 5 September 2013

\section{References}

1. Niswander L: Pattern formation: old models out on a limb. Nat Rev Genet 2003, 4:133-143.

2. Jin EJ, Choi YA, Park EK, Bang OS, Kang SS: MMP-2 functions as a negative regulator of chondrogenic cell condensation via down-regulation of the FAK-integrin beta1 interaction. Dev Biol 2007, 308(2):474-484. 
3. Oh CD, Chang SH, Yoon YM, Lee SJ, Lee YS, Kang SS, Chun JS: Opposing role of mitogen-activated protein kinase subtypes, erk-1/2 and p38, in the regulation of chondrogenesis of mesenchymes. J Biol Chem 2000, 275(8):5613-5619.

4. Mitsugi S, Ariyoshi W, Okinaga T, Kaneuji T, Kataoka Y, Takahashi T, Nishihara $\mathrm{T}$ : Mechanisms involved in inhibition of chondrogenesis by activin-A. Biochem Biophys Res Commun 2012, 420(2):380-384.

5. Arthur A, Zannettino A, Panagopoulos R, Koblar SA, Sims NA, Stylianou C, Matsuo K, Gronthos S: EphB/ephrin-B interactions mediate human MSC attachment, migration and osteochondral differentiation. Bone 2011, 48(3):533-542.

6. Forsyth $C B$, Pulai J, Loeser RF: Fibronectin fragments and blocking antibodies to alpha2beta 1 and alpha5beta1 integrins stimulate mitogenactivated protein kinase signaling and increase collagenase 3 (matrix metalloproteinase 13) production by human articular chondrocytes. Arthritis Rheum 2002, 46(9):2368-2376

7. Loeser RF, Forsyth CB, Samarel AM, Im HJ: Fibronectin fragment activation of proline-rich tyrosine kinase PYK2 mediates integrin signals regulating collagenase- 3 expression by human chondrocytes through a protein kinase C-dependent pathway. J Biol Chem 2003, 278(27):24577-24585.

8. Mengshol JA, Vincenti MP, Coon Cl, Barchowsky A, Brinckerhoff CE: Interleukin-1 induction of collagenase 3 (matrix metalloproteinase 13) gene expression in chondrocytes requires p38, c-Jun N-terminal kinase, and nuclear factor kappaB: differential regulation of collagenase 1 and collagenase 3. Arthritis Rheum 2000, 43(4):801-811.

9. Kim D, Song J, Kim S, Park HM, Chun CH, Sonn J, Jin EJ: MicroRNA-34a modulates cytoskeletal dynamics through regulating RhoA/Rac1 crosstalk in chondroblasts. J Biol Chem 2012, 287(15):12501-12509.

10. Kim D, Song J, Kim S, Chun CH, Jin EJ: MicroRNA-34a regulates migration of chondroblast and IL-1 $\beta$-induced degeneration of chondrocytes by targeting EphA5. Biochem Biophys Res Commun 2011, 415(4):551-557.

11. Kim DK, Song JS, Jin EJ: MicroRNA-221 regulates chondrogenic differentiation through promoting proteosomal degradation of slug by targeting Mdm2. J Biol Chem 2010, 285(35):26900-26907.

12. Kobayashi T, Lu J, Cobb BS, Rodda SJ, McMahon AP, Schipani E, Merkenschlager M, Kronenberg HM: Dicer-dependent pathways regulate chondrocyte proliferation and differentiation. Proc Natl Acad Sci USA 2008, 105(6):1949-1954.

13. Lancman JJ, Caruccio NC, Harfe BD, Pasquinelli AE, Schageman JJ, Pertsemlidis A, Fallon JF: Analysis of the regulation of lin-41 during chick and mouse limb development. Dev Dyn 2005, 234(4):948-960.

14. Hornstein E, Mansfield JH, Yekta S, Hu JK, Harfe BD, McManus MT, Baskerville S, Bartel DP, Tabin CJ: The microRNA miR-196 acts upstream of Hoxb8 and Shh in limb development. Nature 2005, 438(7068):671-674.

15. Salbaum JM, Kappen C: Cloning and expression of nope, a new mouse gene of the immunoglobulin superfamily related to guidance receptors. Genomics 2000, 64(1):15-23.

16. Watanabe $\mathrm{Y}$, Nakamura $\mathrm{H}$ : Nuclear translocation of intracellular domain of Protogenin by proteolytic cleavage. Dev Growth Differ 2012, 54(2):167-176.

17. Wong YH, Lu AC, Wang YC, Cheng HC, Chang C, Chen PH, Yu JY, Fann MJ: Protogenin defines a transition stage during embryonic neurogenesis and prevents precocious neuronal differentiation. J Neurosci 2010, 30(12):4428-4439.

18. Ito K, Nakamura $H$, Watanabe $Y$ : Protogenin mediates cell adhesion for ingression and re-epithelialization of paraxial mesodermal cells. Dev Biol 2011, 351(1):13-24.

19. Toyoda R, Nakamura H, Watanabe Y: Identification of protogenin, a novel immunoglobulin superfamily gene expressed during early chick embryogenesis. Gene Expr Patterns 2005, 5(6):778-785.

20. Goldring MB, Birkhead JR, Suen LF, Yamin R, Mizuno S, Glowacki J, Arbiser $J$, Apperley JF: Interleukin-1 beta-modulated gene expression in immortalized human chondrocytes. J Clin Invest 1994, 94(6):2307-2316.

21. Demoor-Fossard M, Redini F, Boittin M, Pujol JP: Expression of decorin and biglycan by rabbit articular chondrocytes. Effects of cytokines and phenotypic modulation. Biochim Biophys Acta 1998, 1398(2):179-191.

22. Amin AR, Abramson SB: The role of nitric oxide in articular cartilage breakdown in osteoarthritis. Curr Opin Rheumatol 1998, 10(3):263-268.

23. Buxton PG, Kostakopoulou K, Brickell P, Thorogood P, Ferretti P: Expression of the transcription factor slug correlates with growth of the limb bud and is regulated by FGF-4 and retinoic acid. Int J Dev Biol 1997, 41(4):559-568.
24. Weston AD, Rosen V, Chandraratna RA, Underhill TM: Regulation of skeletal progenitor differentiation by the BMP and retinoid signaling pathways. J Cell Biol 2000, 148(4):679-690.

25. Lefebvre V, Peeters-Joris C, Vaes G: Modulation by interleukin 1 and tumor necrosis factor alpha of production of collagenase, tissue inhibitor of metalloproteinases and collagen types in differentiated and dedifferentiated articular chondrocytes. Biochim Biophys Acta 1990, 1052(3):366-378

26. Yoon YM, Kim SJ, Oh CD, Ju JW, Song WK, Yoo YJ, Huh TL, Chun JS: Maintenance of differentiated phenotype of articular chondrocytes by protein kinase $C$ and extracellular signal-regulated protein kinase. J Biol Chem 2002, 277(10):8412-8420.

27. Villiger PM, Lotz M: Differential expression of TGF beta isoforms by human articular chondrocytes in response to growth factors. J Cell Physiol 1992, 151(2):318-325.

28. Wang X, Manner PA, Horner A, Shum L, Tuan RS, Nuckolls GH: Regulation of MMP-13 expression by RUNX2 and FGF2 in osteoarthritic cartilage. Osteoarthritis Cartilage 2004, 12(12):963-973.

29. Blaney Davidson EN, Remst DF, Vitters EL, van Beuningen HM, Blom AB, Goumans MJ, van den Berg WB, van der Kraan PM: Increase in ALK1/ALK5 ratio as a cause for elevated MMP-13 expression in osteoarthritis in humans and mice. J Immunol 2009, 182(12):7937-7945.

30. Woessner JF, Gunja-Smith Z: Role of metalloproteinases in human osteoarthritis. J Rheumatol 1991, 18(2):99-101.

31. Glasson SS, Chambers MG, Van Den Berg WB, Little CB: The OARSI histopathology initiative - recommendations for histological assessments of osteoarthritis in the mouse. Osteoarthritis Cartilage 2010, 18(supple3):s17-s23.

32. Wienholds $\mathrm{E}$, Plasterk RH: MicroRNA function in animal development. FEBS Lett 2005, 579(26):5911-5922.

33. Chen JF, Mandel EM, Thomson JM, Wu Q, Callis TE, Hammond SM, Conlon FL, Wang DZ: The role of microRNA-1 and microRNA-133 in skeletal muscle proliferation and differentiation. Nat Genet 2006, 38(2):228-233.

34. Denli AM, Cao X, Gage FH: miR-9 and TLX: chasing tails in neural stem cells. Nat Struct Mol Biol 2009, 16(4):346-347.

35. Wan HY, Guo LM, Liu T, Liu M, Li X, Tang H: Regulation of the transcription factor NF-kappaB1 by microRNA-9 in human gastric adenocarcinoma. Mol Cancer 2010, 9:16.

36. Jones SW, Watkins G, Le Good N, Roberts S, Murphy CL, Brockbank SM, Needham MR, Read SJ, Newham P: The identification of differentially expressed microRNA in osteoarthritic tissue that modulate the production of TNF-alpha and MMP13. Osteoarthritis Cartilage 2009, 17(4):464-472.

37. Rajagopalan S, Deitinghoff L, Davis D, Conrad S, Skutella T, Chedotal A, Mueller BK, Strittmatter SM: Neogenin mediates the action of repulsive guidance molecule. Nat Cell Biol 2004, 6(8):756-762.

38. Conrad S, Genth H, Hofmann F, Just I, Skutella T: Neogenin-RGMa signaling at the growth cone is bone morphogenetic proteinindependent and involves RhoA, ROCK, and PKC. J Biol Chem 2007, 282(22):16423-16433.

39. Mawdsley DJ, Cooper HM, Hogan BM, Cody SH, Lieschke GJ, Heath JK: The Netrin receptor Neogenin is required for neural tube formation and somitogenesis in zebrafish. Dev Biol 2004, 269(1):302-315.

40. Blanco FJ, Guitian R, Vázquez-Martul E, de Toro FJ, Galdo F: Osteoarthritis chondrocytes die by apoptosis. A possible pathway for osteoarthritis pathology. Arthritis Rheum 1998, 41(2):284-289.

41. Sharif M, Whitehouse A, Sharman P, Perry M, Adams M: Increased apoptosis in human osteoarthritic cartilage corresponds to reduced cell density and expression of caspase-3. Arthritis Rheum 2004, 50(2):507-515

42. Grishko V, Xu M, Ho R, Mates A, Watson S, Kim JT, Wilson GL, Pearsall AW 4th: Effects of hyaluronic acid on mitochondrial function and mitochondria-driven apoptosis following oxidative stress in human chondrocytes. J Biol Chem 2009, 284(14):9132-9139.

43. Cawston TE, Wilson AJ: Understanding the role of tissue degrading enzymes and their inhibitors in development and disease. Best Pract Res Clin Rheumatol 2006, 20(5):983-1002.

44. Zemmyo M, Meharra EJ, Kühn K, Creighton-Achermann L, Lotz M: Accelerated, aging-dependent development of osteoarthritis in alpha1 integrin-deficient mice. Arthritis Rheum 2003, 48(10):2873-2880. 
45. Yang C, Li SW, Helminen HJ, Khillan JS, Bao Y, Prockop DJ: Apoptosis of chondrocytes in transgenic mice lacking collagen II. Exp Cell Res 1997, 235(2):370-373.

46. Choi YA, Kim DK, Bang OS, Kang SS, Jin EJ: Secretory phospholipase A2 promotes MMP-9-mediated cell death by degrading type I collagen via the ERK pathway at an early stage of chondrogenesis. Biol Cell 2009, 102(2):107-119.

47. Fosang AJ, Last K, Knauper V, Murphy G, Neame PJ: Degradation of cartilage aggrecan by collagenase-3 (MMP-13). FEBS Lett 1996, 380:17-20.

48. Neuhold LA, Killar L, Zhao W, Sung ML, Warner L, Kulik J, Turner J, Wu W Billinghurst C, Meijers T, Poole AR, Babij P, DeGennaro LJ: Postnatal expression in hyaline cartilage of constitutively active human collagenase-3 (MMP-13) induces osteoarthritis in mice. J Clin Invest 2001, 107(1):35-44.

49. Glasson SS, Askew R, Sheppard B, Carito B, Blanchet T, Ma HL, Flannery CR, Peluso D, Kanki K, Yang Z, Majumdar MK, Morris EA: Deletion of active ADAMTS5 prevents cartilage degradation in a murine model of osteoarthritis. Nature 2005, 434(7033):644-648.

50. Stanton H, Rogerson FM, East CJ, Golub SB, Lawlor KE, Meeker CT, Little CB, Last K, Farmer PJ, Campbell IK, Fourie AM, Fosang AJ: ADAMTS5 is the major aggrecanase in mouse cartilage in vivo and in vitro. Nature 2005, 434(7033):648-652.

51. Yamasaki K, Nakasa T, Miyaki S, Ishikawa M, Deie M, Adachi N, Yasunaga Y, Asahara H, Ochi M: Expression of MicroRNA-146a in osteoarthritis cartilage. Arthritis Rheum 2009, 60(4):1035-1041.

52. Li X, Gibson G, Kim JS, Kroin J, Xu S, van Wijnen AJ, Im HJ: MicroRNA-146a is linked to pain-related pathophysiology of osteoarthritis. Gene 2011, 480(1-2):34-41.

53. Iliopoulos D, Malizos KN, Oikonomou P, Tsezou A: Integrative microRNA and proteomic approaches identify novel osteoarthritis genes and their collaborative metabolic and inflammatory networks. PLoS One 2008, 3(11):e3740

54. Miyaki S, Nakasa T, Otsuki S, Grogan SP, Higashiyama R, Inoue A, Kato Y, Sato T, Lotz MK, Asahara H: MicroRNA-140 is expressed in differentiated human articular chondrocytes and modulates interleukin-1 responses. Arthritis Rheum 2009, 60(9):2723-2730.

55. Miyaki S, Sato T, Inoue A, Otsuki S, Ito Y, Yokoyama S, Kato Y, Takemoto F, Nakasa T, Yamashita S, Takada S, Lotz MK, Ueno-Kudo H, Asahara H: MicroRNA-140 plays dual roles in both cartilage development and homeostasis. Genes Dev 2010, 24(11):1173-1185.

56. Ryu JH, Kim SJ, Kim SH, Oh CD, Hwang SG, Chun CH, Oh SH, Seong JK, Huh $T L$, Chun JS: Regulation of the chondrocyte phenotype by beta-catenin. Development 2002, 129:5541-5550.

57. Hautier A, Salentey V, Aubert-Foucher E, Bougault C, Beauchef G, Ronzière MC, De Sobarnitsky S, Paumier A, Galéra P, Piperno M, Damour O, MalleinGerin F: Bone morphogenetic protein-2 stimulates chondrogenic expression in human nasal chondrocytes expanded in vitro. Growth Factors 2008, 26(4):201-211.

58. Crounch SPM: The use of ATP bioluminescence as a measure of cell proliferation and cytotoxicity. J Immunol Methods 1993, 160(1):81-88.

\section{doi:10.1186/1478-811X-11-66}

Cite this article as: Song et al:: MicroRNA-9 regulates survival of chondroblasts and cartilage integrity by targeting protogenin. Cell Communication and Signaling 2013 11:66.

\section{Submit your next manuscript to BioMed Central and take full advantage of:}

- Convenient online submission

- Thorough peer review

- No space constraints or color figure charges

- Immediate publication on acceptance

- Inclusion in PubMed, CAS, Scopus and Google Scholar

- Research which is freely available for redistribution 